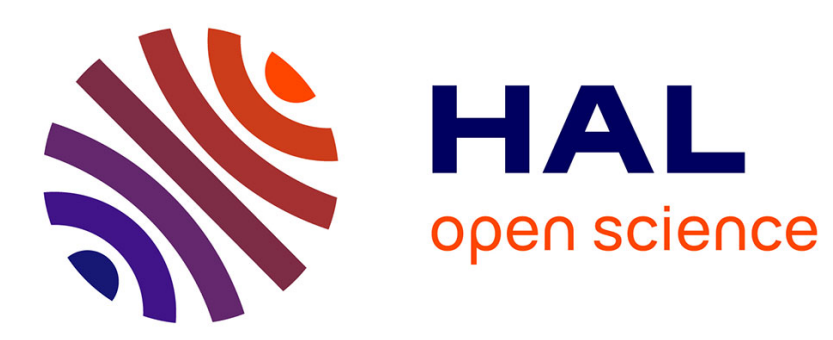

\title{
The metabolic costs of fighting and host exploitation in a seed-drilling parasitic wasp
}

\author{
Romain Boisseau, H. Arthur Woods, Marlène Goubault
}

\section{To cite this version:}

Romain Boisseau, H. Arthur Woods, Marlène Goubault. The metabolic costs of fighting and host exploitation in a seed-drilling parasitic wasp. Journal of Experimental Biology, 2017, 220 (21), pp.39553966. 10.1242/jeb.160887 . hal-02146247

\section{HAL Id: hal-02146247 \\ https://hal.science/hal-02146247}

Submitted on 3 Jun 2019

HAL is a multi-disciplinary open access archive for the deposit and dissemination of scientific research documents, whether they are published or not. The documents may come from teaching and research institutions in France or abroad, or from public or private research centers.
L'archive ouverte pluridisciplinaire HAL, est destinée au dépôt et à la diffusion de documents scientifiques de niveau recherche, publiés ou non, émanant des établissements d'enseignement et de recherche français ou étrangers, des laboratoires publics ou privés. 


\title{
The metabolic costs of fighting and host exploitation in a seed-drilling parasitic wasp
}

\author{
Romain P. Boisseau ${ }^{1,2,3, *}$, H. Arthur Woods ${ }^{2}$ and Marlène Goubault ${ }^{1}$
}

\begin{abstract}
Oviposition sites may be challenging and energetically costly to access for females in the presence of competitors contesting that resource. Additionally, oviposition sites may be difficult to reach, and penetrating a hard substrate can raise energy costs. In the seeddrilling parasitic wasp Eupelmus vuilleti, females actively fight with conspecific competitors over access to hosts. They are often observed laying eggs on already parasitized hosts (superparasitism) living inside cowpea seeds despite the resulting larval competition. Using flow-through respirometry, we quantified the metabolic costs of fighting and of drilling through the seed to access the host, to understand the wasp's fighting strategies and the occurrence of superparasitism. Agonistic interactions such as kicks or pushes generated very small instantaneous costs, but the females that won their contests had higher pre-contest metabolic rates, suggesting a potential long-term cost associated with dominance. We also found that drilling holes through the seed accounted for approximately $15 \%$ of a wasp's estimated daily energy budget, and that females can reduce these drilling costs by reusing existing holes. Because exploiting new seeds incurs both drilling costs and the risk of fights, it appears cost effective in some situations for females to avoid confrontations and lay eggs in existing holes, on already parasitized hosts. Our study helps explain the evolution of superparasitism in this system.
\end{abstract}

KEY WORDS: Eupelmus vuilleti, Flow-through respirometry, Contest
resolution, Resource value, Resource holding potential, Oviposition
costs

\section{INTRODUCTION}

Game theoretic studies have identified various asymmetries between two contestants that are liable to influence contest outcomes; namely, the ability to acquire and retain resources (resource-holding potential) (Maynard Smith and Parker, 1976; Parker, 1974), the value of the resource (Arnott and Elwood, 2008; Maynard Smith and Parker, 1976) and ownership status (Leimar and Enquist, 1984; Maynard Smith and Parker, 1976). These asymmetries influence the costs and benefits associated with fighting, often in different ways for the two contestants. Typically, such costs and benefits depend on two limited resources: time and energy (Danchin et al., 2005; Krebs, 2008).

\footnotetext{
${ }^{1}$ Institut de Recherche sur la Biologie de l'Insecte, UMR 7261 CNRS - Université François-Rabelais de Tours, 37200 Tours, France. ${ }^{2}$ Division of Biological Science, University of Montana, Missoula, MT 59812, USA. ${ }^{3}$ Département de Biologie, Ecole Normale Supérieure, 46 rue d’UIm, 75005 Paris, France.

*Author for correspondence (romain1.boisseau@umontana.edu)

D R.P.B., 0000-0003-4317-1064
}

Received 7 April 2017; Accepted 8 September 2017
Although this remains a key assumption in most game theoretic models (Maynard Smith, 1974; Maynard Smith and Parker, 1976, 1973), studies quantifying the costs of fighting are scarce beyond those that have measured contest duration (Austad, 1983; Hack, 1997; Hardy and Briffa, 2013; Riechert, 1988; Singer and Riechert, 1995). Contest duration is often assumed to be correlated with different costs associated with escalated fights such as energy expenditure (Briffa and Sneddon, 2007), physical injuries (Neat et al., 1998), greater exposure to predators (Dunn et al., 2004; Jakobsson et al., 1995), lost feeding opportunities (Chelazzi et al., 1983) or the production of stress-related hormones causing immunosuppression (Adamo and Parsons, 2006). Among those costs, direct energetic costs may play a critical role in contest resolution. Competition over access to mates, territories or oviposition sites may induce substantial energetic costs that influence strategic decision making and constrain fighting behavior (reviewed in Briffa and Sneddon, 2007). Violent confrontations over extended periods of time cause exhaustion in the red deer (Clutton-Brock and Albon, 1979), and significant metabolic costs of fighting have also been observed in several systems (crabs: Mowles et al., 2009; Rovero et al., 2000; Smith and Taylor, 1993; fishes: Copeland et al., 2011; Neat et al., 1998; spiders: DeCarvalho et al., 2004; crickets: Hack, 1997).

Many of the metabolic costs associated with resource or mate access, including fighting, may be additive. First, accessing and exploiting the contested resource may be energetically costly even in the absence of competitors. This cost is likely to influence the willingness of individuals to fight by affecting the net resource value (Murray and Gerrard, 1985; Stockermans and Hardy, 2013). Oviposition in parasitoids, for example, is particularly challenging as they must find hosts, which can live in places that are difficult to reach [e.g. under bark, inside galls or even inside other insects (hyperparasitoids)] (Godfray, 1994). In hymenopterans, these challenges have driven the extreme diversification of ovipositor structure and function (Kundanati and Gundiah, 2014; Quicke et al., 1999). Despite carrying an effective ovipositor, boring through a substrate likely induces costs in time and energy (Hildner and Soule, 2004; Luna and Antinuchi, 2006). Yet, we are not aware of any study dealing with the energy expenditure associated with substrate boring in parasitic wasps. Second, fights over access to resources or mates may have large metabolic costs that are incurred infrequently and only during brief fighting periods. For example, male Acheta domesticus consume oxygen at rates up to eight times resting levels during fights over space (Hack, 1997). Similar studies suggest that fighting induces instantaneous energetic costs, which may constrain fighting intensity if demand exceeds capacity or if anaerobic respiration produces too much metabolic waste such as lactic acid (Copeland et al., 2011; DeCarvalho et al., 2004; Neat et al., 1998; Sneddon et al., 1999). Finally, resting metabolic rate (RMR) is sometimes correlated with the capacity of individuals to win agonistic interactions. For instance, dominant individuals show a 
higher RMR in freshwater prawns and salmon (Brown et al., 2003; Cutts et al., 1999; Metcalfe et al., 1995). There are potential benefits associated with a high RMR, including a higher metabolic scope (i.e. the difference between maximum metabolic rate and minimal RMR) allowing for more active lifestyles (Clarke and Fraser, 2004). However, the positive link between RMR and metabolic scope is not universal (Koteja, 1987). Although instantaneous energetic costs associated with a higher resource holding potential (e.g. bigger body or weapons) may be small, over time these costs can accumulate. For example, while bearing a large weapon is advantageous in male-male combat, it can coincide with a substantially higher RMR (Allen and Levinton, 2007; D. O'Brien, R.P.B., U. Somjee, M. Deull, E. McCullough, H.A.W., C. Miller and D. J. Emlen, unpublished). High RMR associated with dominance may deplete energy reserves, potentially with larger effects than intense short-term costs.

The present study is, to our knowledge, the first to examine the metabolic costs of the entire sequence of resource exploitation from fighting against contestants to directly exploiting the resource. We studied female-female contests for access to hosts in the solitary ectoparasitoid wasp Eupelmus vuilleti (Crawford 1913) (Hymenoptera: Eupelmidae). Females of this species oviposit on larvae and pupae of bruchid beetles, including Callosobruchus maculatus (Coleoptera: Bruchidae), living inside cowpea seeds, Vigna unguiculata (Fabacae) (Terrasse and Rojas-Rousse, 1986). A female may spend an hour or more exploiting a host, notably by drilling one or several holes through the seed into the chamber where the larva resides. A single host can only support the development of one parasitoid larva (i.e. solitary parasitoid). Unparasitized hosts are thus limited resources of high quality over which females may fight with other conspecific females, by chasing or kicking, to drive them away and so exploit the host alone (Mohamad et al., 2010). In E. vuilleti, the outcome of femalefemale contests is mainly driven by asymmetries in the subjective resource value (Mohamad et al., 2010). This differential value of the same resource is based on the previous experience of resource availability and/or physiological status of each contestant. In particular, females carrying more ready-to-lay eggs or those that have been deprived of hosts (i.e. having experienced an environment poor in hosts) are more aggressive and more likely to win host access (Mohamad et al., 2010). In contrast, differences in body mass (i.e. resource holding potential) between contestants, which may range from 0.7 to $2.4 \mathrm{mg}$ (this study), does not influence contest outcome in this system (Mohamad et al., 2011). Additionally, ownership status also affects the occurrence of fights in E. vuilleti. When owners have been only briefly in contact with the host-containing seed (i.e. ownership is not yet established), intruders often initiate fights (Mohamad et al., 2012). In contrast, when owners possess the resource for a long time (i.e. they are ready to parasitize the host), intruders do not fight but rather wait for the resident female to depart before laying additional eggs on the host (superparasitism). Hence, intruders adopt different strategies (waiting or fighting) depending on the stage reached by the owner in her oviposition sequence. Such observations suggest that the balance between costs and benefits of behaviors changes in relation to ownership asymmetry. When the host is still unparasitized, the advantage of fighting is clear. However, understanding the advantages of waiting to access a low-quality host is less straightforward. Intriguingly for a solitary parasitoid, superparasitism seems common and, in competitive environments, females accept and even prefer laying their eggs on already parasitized hosts (Jaloux et al., 2004). In this case, larval fights will occur and only one individual will be able to survive and develop (Goubault et al., 2003; Jaloux et al., 2004; Mohamad et al., 2011). To avoid the risk of larval competition, a female may also destroy the competitor's eggs before laying her own (Leveque et al., 1993). Females save time by laying their egg on already parasitized hosts, as drilling through the seed is time consuming and represents on average $43 \%$ of the total time required to lay one egg (Jaloux et al., 2004).

To understand the evolution of fighting and oviposition behaviors in E. vuilleti, we used flow-through respirometry to measure the metabolic costs of both dyadic fights between females and seed drilling. We investigated whether metabolic costs could explain female fighting decisions and hypothesized that fighting would have a significant cost in terms of both an increase in metabolic rate compared with pre-fighting metabolic rate and its impact on energy budgets. Under this hypothesis, adopting a 'waiting strategy' and avoiding confrontation enables intruders to save the high metabolic cost of fighting against a resident that is typically more likely to win (Mohamad et al., 2012). Additionally, we suspected that drilling holes through cowpea seeds would also be energetically expensive. Thus, by waiting for a rival to oviposit on a host and then reusing the existing hole to superparasitize, a female may pay the cost of parasitizing a low-quality host (i.e. already parasitized) but will avoid the costs of both fighting and drilling. We first tested whether pre-contest metabolic rate was correlated with the probability of winning the contest and whether dominance would be costly in this system. We then investigated whether fighting per se induced metabolic costs. Because kicks or pushes occur over very short periods of time, we hypothesized that contestants might experience rapid increases in ATP turnover rates that would result in bursts of $\mathrm{CO}_{2}$ emission. Finally, we quantified energy expenditure during the entire drilling and oviposition sequence, on both healthy and already parasitized hosts.

\section{MATERIALS AND METHODS Parasitoid rearing}

Infested cowpea seeds were collected in crop fields in North Togo (Dapaong area) in 2007, then brought to the laboratory (IRBI, University of Tours, France) for parasitoid development. The parasitoids were reared in the laboratory on larvae and pupae of C. maculatus following standard procedures (see Jaloux, 2004). All experimental procedures were carried out in a climate-controlled room mimicking the conditions the wasp experiences in the wild: $30^{\circ} \mathrm{C}, 70 \%$ relative humidity and $13 \mathrm{~h}: 11 \mathrm{~h}$ light:dark.

\section{Flow-through respirometry}

Metabolic rate was estimated as the rate of $\mathrm{CO}_{2}$ production $\left(\dot{M}_{\mathrm{CO}_{2}}\right)$ using flow-through respirometry. $\mathrm{CO}_{2}$ concentration was measured using a Licor LI-7000 $\mathrm{CO}_{2} / \mathrm{H}_{2} \mathrm{O}$ analyzer (Licor, Lincoln, NB, USA) in differential mode, which was calibrated frequently using $\mathrm{CO}_{2}$-free air and 4880 ppm $\mathrm{CO}_{2}$ in $\mathrm{N}_{2}$ (Messer France SAS, Carbon Blanc, France). Flow rates of gas were set to $250 \mathrm{ml} \mathrm{min}^{-1}$ (standard temperature and pressure) by a mass flow controller (Unit Instruments, Yorba Linda, CA, USA; 0-250 standard cubic centimeters per minute, $\mathrm{sccm}$, calibrated for air) connected to a set of controlling electronics (MFC-4, Sable Systems International, Las Vegas, NV, USA). Flow rate was chosen to balance detectability of $\mathrm{CO}_{2}$ and the temporal resolution of metabolic events (Lighton, 2008). All gases circulated between the instruments in $3 \mathrm{~mm}$ inner-diameter plastic tubing (Bevaline-IV, Cole Parmer, Vernon Hills, IL, USA). Dry, $\mathrm{CO}_{2}$-free air was first directed through the reference cell (referred to as cell A), which measured the fractional $\mathrm{CO}_{2}$ concentration in incurrent $\operatorname{air}\left(\mathrm{FI}_{\mathrm{I}_{2}}\right)$, 


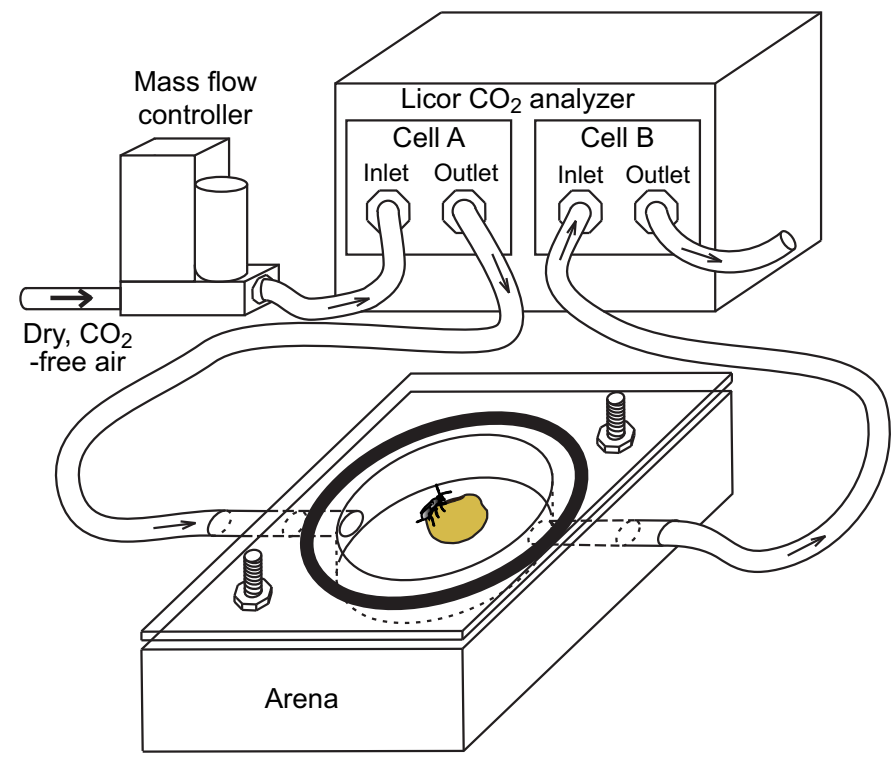

Fig. 1. Experimental set-up. The arena was custom made from Plexiglas. The inside was cylindrical with a diameter of $25 \mathrm{~mm}$ and depth of $10 \mathrm{~mm}$, for a total volume of approximately $5 \mathrm{ml}$. The chamber was sealed using two screws that tightened a transparent Plexiglas cover onto a viton O-ring (drawn here as a thick black ellipse). Arrows indicate the direction of the air stream.

then through the experimental chamber and into the measurement side of the analyzer (referred to as cell B), which measured the fractional $\mathrm{CO}_{2}$ concentration in excurrent air $\left(\mathrm{FE}_{\mathrm{EO}_{2}}\right)$. The $5 \mathrm{ml}$ sealed chamber was custom made from Plexiglas for this study (Fig. 1). The transparent cover allowed us to observe wasp activity in real time under a microscope during trials. Data were collected using ExpeData software (v. 1.1.9; Sable Systems) receiving digital signals from an analog-to-digital converter (UI2, Sable Systems), which itself received analog signals from the instruments. To introduce either a bean or wasps into the chamber, we paused the recording of $\mathrm{CO}_{2}$ concentration in Expedata and briefly opened the chamber before sealing it again. We resumed the recording in ExpeData after chamber readings stabilized (less than $30 \mathrm{~s}$ post-introduction). Measurement periods lasted a maximum of 100 min per run. We estimated the delay between the occurrence of a $\mathrm{CO}_{2}$ burst and its detection by the respirometer by quickly opening $(<1 \mathrm{~s})$ and immediately closing the entrance of the chamber to provoke a brief artificial $\mathrm{CO}_{2}$ burst inside the chamber. There was an average delay of $4 \mathrm{~s}$ before the onset of the measurement of the resulting peak, and $6 \mathrm{~s}$ to reach the maximum height of the peak. Peak width was approximately $10 \mathrm{~s}$. We sampled at $1 \mathrm{~Hz}$. Batholomew's instantaneous correction was applied to the raw traces (Bartholomew et al., 1981) to account for washout and accurately resolve short-term events.

\section{Experimental procedures}

During the experiments, we observed the wasps under a microscope and used JWatcher software (v. 1.0, http://www.jwatcher.ucla.edu/) to record the time of occurrence of each behavior while their $\mathrm{CO}_{2}$ production was simultaneously recorded. All recorded behaviors are described in Table 1. JWatcher and ExpeData were synchronized for analysis.

For all experiments, we used adult females 2-3 days after emergence. Females were immediately collected upon emergence from the pupal case and placed individually in Petri dishes to control for intraspecific experience. They were provided with a seed containing a single host (replaced daily), a wet cotton ball and one freshly emerged adult male for mating. To motivate oviposition, the host-containing seed was removed from the Petri dish on the afternoon or evening before the experiment (i.e. $16 \mathrm{~h}$ before, on average). All wasps were weighed at the end of each trial (Mettler Toledo ${ }^{\circledR}$ scale, accurate to $0.01 \mathrm{mg}$ ).

Initially, we measured the metabolic rates of uninfested seeds alone $(n=10)$, seeds containing one live bruchid larva or pupa $(n=15)$, and wasps alone $(n=93)$ by placing them individually in the respirometry chamber for 5 min. Host $\mathrm{CO}_{2}$ production was substantial and not stable over time (Fig. 2A). It was not possible to discriminate the wasp's signal from that of the host when both were present. To eliminate $\mathrm{CO}_{2}$ emissions from hosts, we used bruchid pupae that had been frozen for at least $24 \mathrm{~h}$ (Fig. 2B,C). Frozen seeds containing one freshly dead bruchid pupa were warmed to room temperature for $2 \mathrm{~h}$ before the beginning of the experiment. Female wasps still showed interest and laid eggs on these dead hosts.

During our experiments, the wasps were rarely at complete rest in the chamber, which precluded measurement of true RMR. Instead, we used the mean $\mathrm{CO}_{2}$ production (mean $\dot{M}_{\mathrm{CO}_{2}}$ ) of the wasp alone in the chamber as a reference $\mathrm{CO}_{2}$ production $\left(\dot{M}_{\mathrm{CO}_{2} \text {,ref }}\right)$ to which the $\dot{M}_{\mathrm{CO}_{2}}$ of the different activities was compared. After 2 min alone in the chamber, the wasps showed minimal activity. We verified that $\dot{M}_{\mathrm{CO}_{2}}$ was stable over time after the first 2 min alone in the chamber in 16 trials that lasted at least $30 \mathrm{~min}$ (Fig. S1). Thus, the $\dot{M}_{\mathrm{CO}_{2} \text {,ref }}$ of each wasp was obtained by placing it in the chamber for $5 \mathrm{~min}$ but using only minutes 3-5 to calculate mean $\dot{M}_{\mathrm{CO}_{2}}$.

Table 1. Description of female behaviors recorded in this study

\begin{tabular}{|c|c|}
\hline Behavior & Description \\
\hline \multicolumn{2}{|l|}{ Agonistic behaviors } \\
\hline Chasing & The female chases her opponent. \\
\hline Kicking & The female kicks her opponent with her legs while her ovipositor is inserted inside the seed. \\
\hline Mounting & The female mounts her opponent in an attempt to push her away. \\
\hline Pushing & The female runs towards the opponent and pushes her. \\
\hline \multicolumn{2}{|l|}{ Host exploitation } \\
\hline \multicolumn{2}{|l|}{ Exploration } \\
\hline Walking & The female walks around, exploring the environment. \\
\hline Antennating & The female examines the host-containing seed with her antennae. \\
\hline External probing & The female bends her abdomen and explores the seed surface with the tip of her ovipositor. \\
\hline Drilling & $\begin{array}{l}\text { To start drilling, the female releases the stylus of the ovipositor from the third pair of valves that protect it and help to position it. } \\
\text { The drilling phase ends when the ovipositor is fully inserted into the seed for the first time. }\end{array}$ \\
\hline Internal probing & $\begin{array}{l}\text { Once the ovipositor is fully inserted into the seed, the female can examine the host surface and assess its quality. Repeated } \\
\text { movements of the ovipositor in and out of the seed are observed. This can end with oviposition, when the female stops moving } \\
\text { and her abdomen forms a typical triangular shape for several seconds. }\end{array}$ \\
\hline
\end{tabular}



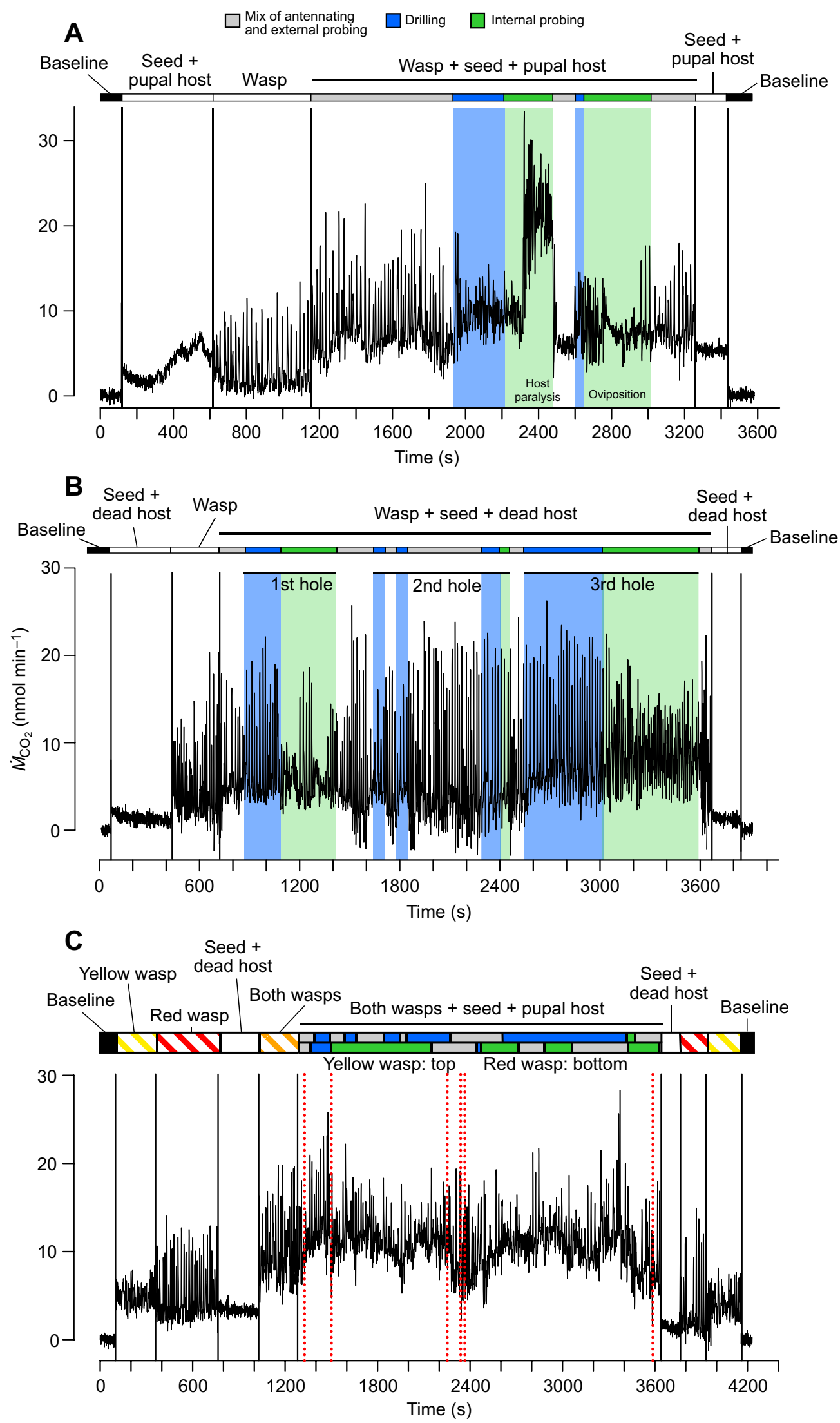

Fig. 2. Long-term traces of $\mathrm{CO}_{2}$ emission. The timeline above each trace indicates what was inside the chamber for each part delimited by vertical black lines. (A) Rate of $\mathrm{CO}_{2}$ production $\left(\dot{M}_{\mathrm{CO}_{2}}\right)$ of a live bruchid pupa inside a cowpea seed and a single wasp interacting with it. (B) $\dot{M}_{\mathrm{CO}}$ of a single wasp interacting with a dead bruchid pupa inside a cowpea seed. (C) $\dot{M}_{\mathrm{CO}_{2}}$ of two female wasps interacting with a dead host inside a cowpea seed. Vertical red dotted lines indicate the onset of brief agonistic interactions. Regular spikes should not be interpreted as noise as they represent cyclic emissions of $\mathrm{CO}_{2}$ from the wasps (see Fig. $\mathrm{S} 1$ ). 
To investigate whether mature egg load is correlated with rates of $\mathrm{CO}_{2}$ production, we estimated it in a separate subset of females $(n=20)$ for which we only measured body mass and $\dot{M}_{\mathrm{CO}_{2} \text {,ref }}$ in the chamber. These females were freeze-killed immediately after the measurement, dissected under a microscope, and the number of mature eggs counted.

\section{The metabolic costs of fighting}

To assess energy expenditure during agonistic interactions, we staged fighting trials inside the respirometry chamber. We used two females that were matched by age (i.e. 2 or 3 days after emergence) and oviposition experience (i.e. one host per day) so that fights were more likely to escalate (Hardy and Briffa, 2013; Mohamad et al., 2010). To distinguish females in the arena, we marked both contestants on the dorsal part of the thorax with a dot of bright yellow or red water-soluble acrylic paint.

For each trial, we used the following chronology: baseline measurement ( $1 \mathrm{~min}$ ), first female alone (either the yellow or red one, $5 \mathrm{~min}$ ), second female alone ( $5 \mathrm{~min}$ ), seed and host alone (5 min), two females together without host $(5 \mathrm{~min})$, trial (two females and host-containing seed), seed and host alone (5 min), second female alone ( $5 \mathrm{~min})$, first female alone ( $5 \mathrm{~min}$ ) and baseline measurement (1 min) (Fig. 2C). The two females were introduced simultaneously into the respirometry chamber for the trial. We liverecorded all behaviors associated with host exploitation as well as agonistic behaviors (Table 1). We ended the trial when a female was clearly observed laying an egg. We considered the female that laid an egg first as the winner of the contest. In cases where females drilled two different holes and both laid an egg in their respective hole within $10 \mathrm{~min}$, we considered the contest as a draw (2 out of 21 trials).

\section{The metabolic costs of drilling}

To measure the metabolic costs of drilling through the seed to reach the host, we recorded the $\dot{M}_{\mathrm{CO}_{2}}$ of a single wasp offered a hostcontaining seed. $\dot{M}_{\mathrm{CO}_{2}}$ was associated with three types of behavior: exploration, drilling and internal probing (Table 1). Before the trial, we measured the $\dot{M}_{\mathrm{CO}_{2}}$ of the seed containing the dead host alone and that of the wasp alone for 5 min each (Fig. 2B). The wasp and the host-containing seed were then introduced together into the chamber. We ended the trial when the wasp did not show any interest in the seed by not climbing on it for $20 \mathrm{~min}$ ( 7 out of 23 trials), or left the seed after oviposition. Immediately after the trial, we again measured $\dot{M}_{\mathrm{CO}_{2}}$ of the host-containing seed in the absence of the female wasp for an additional $5 \mathrm{~min}$.

For each drilling event, we recorded the position of the hole on the seed: cotyledon, eye of the seed and bruchid beetle's egg chorion (Fig. S2). By drilling through the beetle's egg chorion, the wasp might take advantage of the gallery already drilled by the larva to penetrate the seed, and thus save energy and time compared with drilling a new hole. Each hole drilled by the wasps was given a unique ID number associated with its position. Finally, for each drilling event observed, we checked whether the hole was newly drilled or whether it had already been partly or entirely drilled before.

We used 16 different wasps that successfully drilled 26 holes in total (nine of which were not completely drilled as we did not observe the female probing through it). Ten wasps were provided with a new seed containing an unexploited host. The six other wasps were provided with a seed that had already been drilled and exploited by another female on average $20 \mathrm{~min}$ before. That way, we could assess the benefits of reusing a hole that was drilled by a rival.

\section{Data analysis}

Data were extracted and analyzed using R (version 2.15.3; http:/ www.R-project.org). Expedata files were loaded into R using the function read.sscf() (package SableBase). The traces show the relative concentration of $\mathrm{CO}_{2}$ (parts per million, ppm) inside cell B compared with that inside cell A (the reference cell) according to time (sampling frequency: $1 \mathrm{~Hz})$. Raw measures $(\mathrm{ppm})$ were converted to molar rates of $\mathrm{CO}_{2}$ production $\left(\dot{M}_{\mathrm{CO}_{2}}\right)$ using the known flow rate $\left(250 \mathrm{ml} \mathrm{min}^{-1}\right)$ and the Ideal Gas Law:

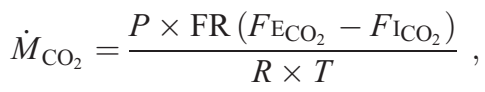

where $\dot{M}_{\mathrm{CO}_{2}}$ is the rate of $\mathrm{CO}_{2}$ production $\left(\mathrm{mol} \mathrm{min}{ }^{-1}\right), F_{\mathrm{E}_{\mathrm{CO}}}$ is the fractional $\mathrm{CO}_{2}$ concentration in excurrent air (measured by cell $\mathrm{B}$ ), $F_{\mathrm{I}_{\mathrm{CO}}}$ is the fractional $\mathrm{CO}_{2}$ concentration in incurrent air (measured by cell A), FR is the flow rate $\left(0.251 \mathrm{~min}^{-1}\right), P$ is pressure ( $1 \mathrm{~atm}), R$ is the gas constant $\left(0.082061 \mathrm{~atm} \mathrm{~K} \mathrm{~K}^{-1} \mathrm{~mol}^{-1}\right)$ and $T$ is temperature $(303.15 \mathrm{~K})$.

Over the long term, $\mathrm{CO}_{2}$ production directly reflects $\mathrm{O}_{2}$ consumption, but the exact ratio depends on which metabolic substrates are being metabolized, and these are not known. As $\mathrm{O}_{2}$ consumption was not assessed in our study, we could not calculate the respiratory exchange ratio $\left(\mathrm{RER}=\dot{M}_{\mathrm{CO}_{2}} / \dot{M}_{\mathrm{O}_{2}}\right)$. Therefore, we chose to use the term rate of $\mathrm{CO}_{2}$ production $\left(\dot{M}_{\mathrm{CO}_{2}}\right)$ instead of metabolic rate to avoid confusion.

\section{Baseline corrections}

The means of baseline measurements at the beginning and at the end of each run were used to model a line between the two means to estimate sensor drift. At each sampling time, the value of the baseline was subtracted from the actual measurement. When studying wasp behavior in the chamber with a freeze-killed host, another baseline was defined, based on the $\mathrm{CO}_{2}$ measurements produced by the seed containing the dead host alone, before and after the actual trial.

\section{Fighting costs}

Agonistic behaviors are isolated events (e.g. kicks, pushes, etc.) that can occur in series. Therefore, we grouped events that were separated by less than $10 \mathrm{~s}$ into a single 'agonistic interaction'. An agonistic interaction begins with the occurrence of its first fighting event and ends $10 \mathrm{~s}$ after the occurrence of the last event to be able to capture the entire hypothetical $\mathrm{CO}_{2}$ burst resulting from the last event, assuming aerobic metabolism only.

We then calculated mean $\dot{M}_{\mathrm{CO}_{2}}$ and maximum instantaneous $\dot{M}_{\mathrm{CO}_{2}}$ (i.e. the highest single $1 \mathrm{~s}$ sample recorded within a given period of time) during each agonistic interaction, which we then

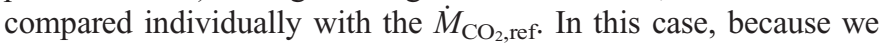
were dealing with two wasps simultaneously, we used the mean and maximum instantaneous $\dot{M}_{\mathrm{CO}_{2}}$ of the two wasps alone as the $\dot{M}_{\mathrm{CO}_{2} \text {,ref }}$ to which the $\dot{M}_{\mathrm{CO}_{2}}$ of agonistic interactions was compared. We verified that the sum of the mean $\dot{M}_{\mathrm{CO}_{2}}$ of each contestant alone was not different from the mean $\dot{M}_{\mathrm{CO}_{2}}$ of the two wasps together in the chamber (Wilcoxon signed-rank test, $V=111, P=0.89$ ). We excluded agonistic interactions for which an event associated with host exploitation (e.g. onset of drilling) may have affected $\dot{M}_{\mathrm{CO}_{2}}$. The wasps have a fast and almost cyclic pattern of $\mathrm{CO}_{2}$ production (Fig. S1). Thus, when measuring maximum instantaneous $\dot{M}_{\mathrm{CO}_{2}}$ (before or during agonistic interactions), a peak reflecting the maximum contribution of the two wasps simultaneously is likely to be sampled. 
Finally, we calculated the cost of a given fight as the difference between the quantity of $\mathrm{CO}_{2}$ produced during all agonistic interactions involved in the contest compared and the quantity produced when resting for the cumulative duration of all agonistic interactions.

\section{Drilling costs}

We calculated the mean $\dot{M}_{\mathrm{CO}_{2}}$ of wasps drilling each hole and probing the host. For each completely drilled hole (i.e. the drilling phase was followed by an internal probing phase), we also recorded the cumulative time needed to drill and probe. We first calculated the metabolic cost of drilling as the increase in mean $\dot{M}_{\mathrm{CO}_{2}}$ during

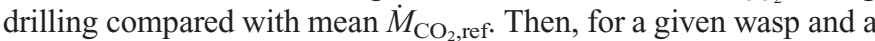
given hole, we multiplied mean $\dot{M}_{\mathrm{CO}_{2}}$ during drilling by the time needed to drill the hole. We also multiplied the mean $\dot{M}_{\mathrm{CO}_{2} \text {,ref }}$ by that same duration. The metabolic cost of drilling was the difference between the quantity of $\mathrm{CO}_{2}$ produced when drilling and the quantity produced when resting for the same amount of time.

\section{Estimation of daily energy expenditure}

The importance of an activity's energetic costs can be estimated by calculating the proportion of an individual's energy budget spent on the activity. Although we did not directly measure daily energy expenditure (DEE) of wasps, we were able to estimate it using data from this study and from the literature. A female wasp typically parasitizes seven hosts per day on average throughout its life (Cortesero, 1994). We observed that on average a female drills 2.3 new holes per host. We then assumed that the wasp would be resting during the dark period (11 h) and active during the light period (13 h). We calculated the energy expenditure at night based on our mean $\dot{M}_{\mathrm{CO}_{2} \text {,ref. }}$ Then, for the active period, we calculated the cumulated energy expenditure of exploiting seven hosts (including drilling and internal probing) based on our measures of mean drilling and probing $\dot{M}_{\mathrm{CO}_{2}}$ and duration. Then, we assumed that the rest of the active period was spent exploring the environment and thus calculated the energy expenditure associated with our measure of exploration $\dot{M}_{\mathrm{CO}_{2}}$.

We calculated both the portion of a typical DEE due to drilling and the additional cost of drilling compared with a hypothetical day that did not involve drilling. We also estimated the additional energetic cost of a fight. Finally, we compared the DEE of a wasp that only reuses holes with that of a wasp that only drills new ones, to quantify the benefit of reusing holes.

It is worth noting that female E. vuilleti are not capable of sustained flight. They may jump and start flying as an escape response, but this behavior is rare (Jaloux, 2004). Therefore, flight is likely to have a negligible effect on DEE. Finally, resting $\dot{M}_{\mathrm{CO}_{2}}$ at night is probably lower than our measure of $\dot{M}_{\mathrm{CO}_{2} \text {,ref }}$ during the day and the active period is likely to involve resting behaviors too. Therefore, our approach is conservative as we probably overestimated the actual DEE of the wasps, which would result in an underestimation of the costs of drilling and fighting.

\section{Statistical analyses}

Statistical analyses of the data were performed using R (http://www. R-project.org). For parametric tests requiring normal distributions, normality was verified both visually using $Q-Q$ plots and with Shapiro-Wilk tests. When building linear models, we checked the normal distribution of the residuals and the absence of any specific patterns in their distribution.

Relative $\mathrm{CO}_{2}$ emission by individual seeds, bruchid hosts and wasps Mean $\dot{M}_{\mathrm{CO}_{2}}$ of individuals was compared using Mann-Whitney tests with Bonferroni correction for multiple testing. The relationships between mass and absolute mean $\dot{M}_{\mathrm{CO}_{2}}$ in wasps and hosts were investigated by fitting a linear model after logtransformation of the data. Finally, the association between egg load and $\dot{M}_{\mathrm{CO}_{2} \text {,ref }}$ was investigated using a linear model that also included body mass as a covariate.

\section{Rate of $\mathrm{CO}_{2}$ production and contest outcome}

Using Mann-Whitney tests, we examined how well $\dot{M}_{\mathrm{CO}_{2} \text {,ref }}$ and body mass predicted whether a wasp won or lost a fight. Additionally, we tested whether winning or losing influenced preand post-contest $\dot{M}_{\mathrm{CO}_{2}}$. As our sample size was relatively small (12 trials for which we recorded both pre- and post-contest $\dot{M}_{\mathrm{CO}_{2}}$ ), a non-parametric Wilcoxon signed-rank test was used. Finally, we investigated whether wasps with matched pre-contest $\dot{M}_{\mathrm{CO}_{2} \text {,ref }}$ had more intense fights with higher attack rates. Attack rate was the total number of agonistic behaviors divided by the time until the first oviposition (calculated for each fight). A non-parametric KruskalWallis rank-sum test was performed to test for an effect of the contestants' pre-contest $\dot{M}_{\mathrm{CO}_{2} \text {,ref }}$ ratio (i.e. higher $\dot{M}_{\mathrm{CO}_{2} \text {,ref }}$ over lower $\dot{M}_{\mathrm{CO}_{2} \text {,ref }}$ for each contestant pair), on the logarithm of the attack rate.

\section{Fighting costs}

Ratios of mean fighting $\dot{M}_{\mathrm{CO}_{2}}$ to mean pre-fighting $\dot{M}_{\mathrm{CO}_{2} \text {,ref }}$ were compared with 1.0 to evaluate the cost of fighting for each agonistic interaction. Similarly, the ratio of maximum instantaneous $\dot{M}_{\mathrm{CO}_{2}}$ during fighting to maximum instantaneous $\dot{M}_{\mathrm{CO}_{2} \text {,ref }}$ was also compared with 1.0. We used one-tailed Student $t$-tests as we assumed that these ratios should be above 1.0 (i.e. agonistic interactions are expected to be energy demanding). Then, we tested the effect of agonistic interaction duration, drilling activity (i.e. no wasps or one wasp drilling during the agonistic interaction) and interaction type (i.e. kicking, pushing, mounting, chasing, pushing + kicking, pushing + mounting) on these ratios. Linear mixed models with contest ID as a random factor were used after log-transformation of the data.

\section{Drilling costs}

Ratios of mean drilling $\dot{M}_{\mathrm{CO}_{2}}$ to $\dot{M}_{\mathrm{CO}_{2} \text {,ref }}$ were compared with 1.0 to investigate the energetic costs of drilling. One-tailed Student $t$-tests were run assuming that this ratio should be greater than 1 (i.e. drilling is an expensive activity). We then tested for the effects of hole position on the seed and hole feature (i.e. new, reused or selfreused) on this ratio, the time needed to drill a hole and the total energetic cost of each hole using linear mixed models with wasp ID as a random factor. Time and the total energetic cost of drilling a hole were log-transformed for the residuals of the corresponding models to be normally distributed. The same statistical analysis was conducted to assess the costs of internal probing of the seed. Finally, we compared the mean metabolic cost of drilling a hole (new or existing) and the mean metabolic cost of a fight using a one-way ANOVA, followed by Tukey HSD post hoc tests.

\section{RESULTS}

\section{Relative $\mathrm{CO}_{2}$ emission by individual seeds, bruchid hosts and wasps}

Uninfested seeds ( $n=10$, mass range 146-274 mg) had a very low $\dot{M}_{\mathrm{CO}_{2}}$ (Fig. 3A). Individual wasps had intermediate levels of $\dot{M}_{\mathrm{CO}_{2} \text {,ref }}(n=93$, mass range $0.66-2.36 \mathrm{mg}$; Fig. 2A), which was also positively correlated with wasp mass $\left(R^{2}=0.13, F_{1,80}=18.53\right.$, $P<0.001$; Fig. 3B). The absolute values of $\mathrm{CO}_{2}$ emission recorded were consistent with a previous study in this system (Casas et al., 2015). Single bruchid hosts (either larvae or pupae) inside single 
B

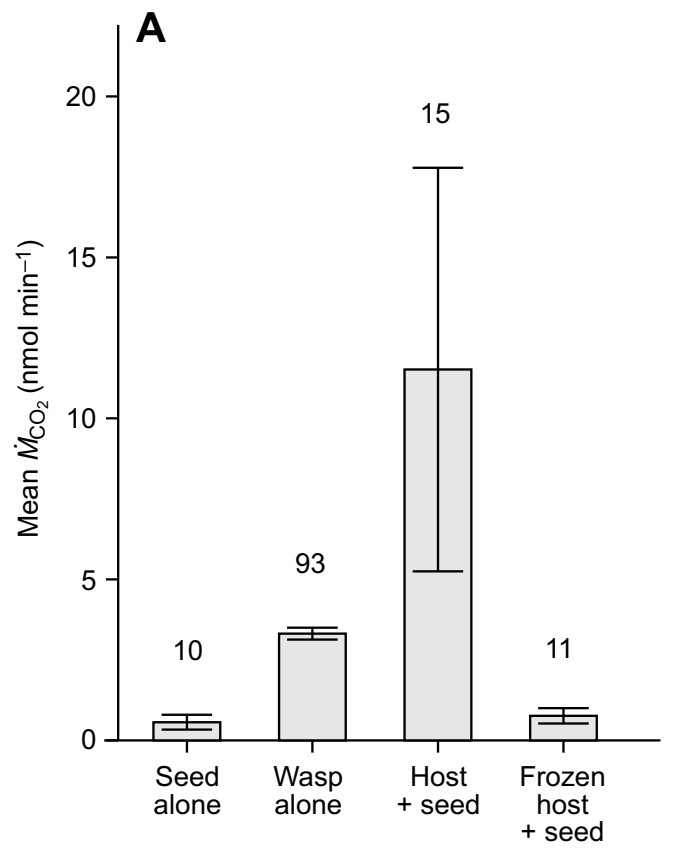

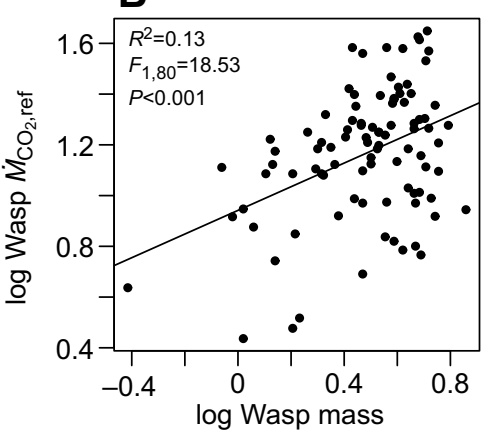

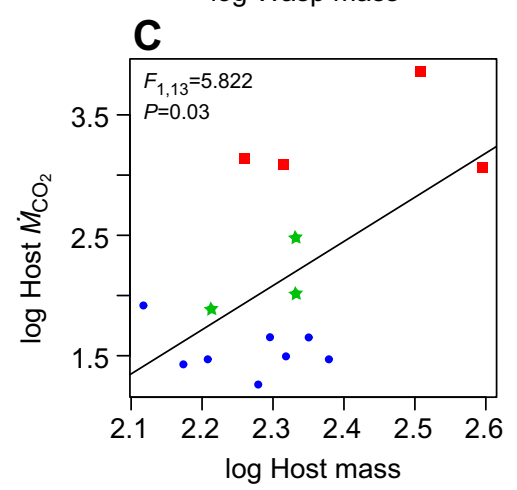

Fig. 3. $\mathrm{CO}_{2}$ production of the three interacting species. (A) $\dot{M}_{\mathrm{CO}_{2}}$ by single uninfested cowpea seeds, female Eupelmus vuilleti wasps $\dot{M}_{\mathrm{CO}_{2} \text {,ref, }}$ and seeds infested by one live bruchid host (larva or pupa within seeds) or one dead host. Error bars indicate 95\% confidence intervals. Numbers above bars indicate sample size. All differences were significant $(P<0.001)$ using Mann-Whitney tests with Bonferroni correction, except between seed alone and frozen host +seed. (B) Logarithmic reference $\dot{M}_{\mathrm{CO}_{2}}\left(\dot{M}_{\mathrm{CO}_{2} \text {,ref }}\right)$ by single female wasps as a function of logarithmic female mass. (C) Logarithmic $\dot{M}_{\mathrm{CO}_{2}}$ by seeds infested with one live bruchid host as a function of logarithmic host mass. Red squares, 3rd instar larvae; green stars, 4th instar larvae; blue dots, pupae. seeds ( $n=15$, mass range $8.3-13.4 \mathrm{mg}$ ) had rates of $\mathrm{CO}_{2}$ emission 3.5 times higher than the wasp $\dot{M}_{\mathrm{CO}_{2} \text {,ref }}$ (Fig. $3 \mathrm{~A}$ ), and these were positively correlated with bruchid mass $\left(F_{1,13}=5.822, P=0.03\right.$; Fig. 3C). This suggests that $\mathrm{CO}_{2}$ is primarily produced by the beetle, not the seed. Pupae had lower $\dot{M}_{\mathrm{CO}_{2} \text {,ref }}$ compared with larvae (respectively 4.76 and $20.0 \mathrm{nmol} \mathrm{min}{ }^{-1}$; Mann-Whitney test, $W=55, P<0.001)$. Single hosts that had been frozen inside single seeds showed the same $\dot{M}_{\mathrm{CO}_{2}}$ as seeds alone, confirming the death of the host inside but not of the dormant seed ( $W=39, P=0.28$; Fig. 3A). Wasp mature egg load was not correlated with $\dot{M}_{\mathrm{CO}_{2} \text {,ref }}$ $\left(F_{1,18}=0.92, P=0.35\right.$, Fig. S3 $)$.

\section{Rate of $\mathrm{CO}_{2}$ production and contest outcome}

Winners had $21 \%$ higher pre-contest mean $\dot{M}_{\mathrm{CO}_{2} \text {,ref }}$ than losers ( $n=19$ fights; Mann-Whitney test, $W=113, P=0.05$; Fig. 4B). However, winners and losers did not differ in body mass $(n=19$ fights; Mann-Whitney test, $W=152.5, P=0.42$; Fig. 4A). There was
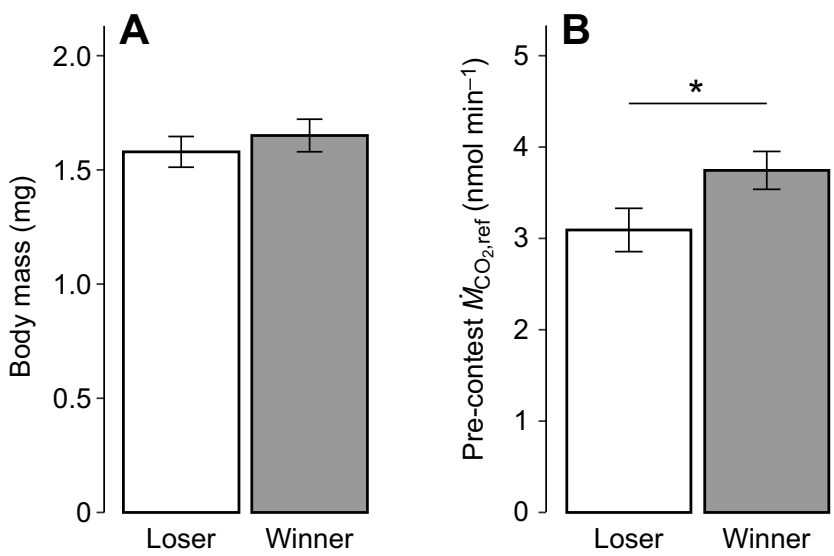

Fig. 4. Differences in mass and pre-contest $\dot{M}_{\mathrm{CO}_{2}}$ between winners and

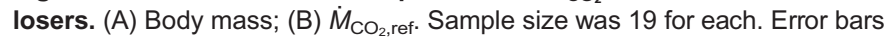
indicate standard error. Asterisk indicates a significant difference $(P=0.05)$. no influence of paint color on contest outcome (yellow wasps won 8 out of 19 resolved contests, binomial test: $P=0.65)$. Neither winners nor losers had post-contest $\dot{M}_{\mathrm{CO}_{2} \text {,ref }}$ that changed significantly compared with pre-contest $\dot{M}_{\mathrm{CO}_{2} \text {,ref }}$ (Wilcoxon signed-rank tests, winners: $V=62, P=0.27$, losers: $V=60, P=0.34$ ). The level of escalation measured as overall attack rate was not significantly correlated with pre-contest $\dot{M}_{\mathrm{CO}_{2} \text {,ref }}$ ratio between the two contestants (Kruskal-Wallis rank sum test, Chi-squared=20, d.f. $=20, P=0.46$; Fig. S4).

\section{Metabolic cost of agonistic interactions}

Fighting events increased the mean $\dot{M}_{\mathrm{CO}_{2}}$ of both contestants combined by $23 \%$ (comparison of ratios with 1: one-tailed Student test: $T_{169}=10.24, P<0.001$ ) and maximum instantaneous $\dot{M}_{\mathrm{CO}_{2}}$ by

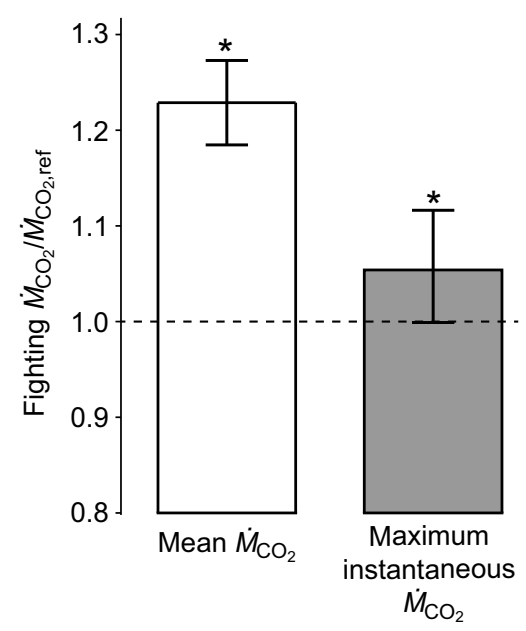

Fig. 5. Ratio of $\mathrm{CO}_{2}$ production during an agonistic interaction to reference $\mathrm{CO}_{2}$ production. Error bars indicate $95 \%$ confidence intervals. Sample size was 169 agonistic interactions. Asterisks indicate a significant difference between the plotted ratio and 1 (dashed line). 
Table 2. Analysis of the effect of fight duration, interaction type and drilling activity during the fight on $\mathrm{CO}_{2}$ production

\begin{tabular}{|c|c|c|c|c|}
\hline Model & Source of variation & d.f. & $F$ & $P$ \\
\hline \multirow[t]{3}{*}{$\log \left(\dot{M}_{\mathrm{CO}_{2}}\right.$ fight $\left./ \dot{M}_{\mathrm{CO}_{2} \text {, ref }}\right) \sim$ duration+drilling+type } & Duration of the interaction & 1 & 1.29 & 0.26 \\
\hline & Drilling (yes or no) & 1 & 39.58 & $<0.001$ \\
\hline & Interaction type & 5 & 2.45 & 0.04 \\
\hline \multirow{3}{*}{$\begin{array}{l}\text { log (maximum fighting i } \dot{M}_{\mathrm{CO}_{2}} / \text { maximum } \\
\left.\text { reference } i \dot{M}_{\mathrm{CO}_{2}}\right) \sim \text { duration+drilling+type }\end{array}$} & Duration of the interaction & 1 & 18.34 & $<0.001$ \\
\hline & Drilling (yes or no) & 1 & 11.98 & $<0.001$ \\
\hline & Interaction type & 5 & 0.07 & 0.99 \\
\hline
\end{tabular}

In the mixed-model ANOVA, trial identity is included as a random factor. $\mathrm{i}_{\mathrm{CO}_{2}}$, instantaneous production of $\mathrm{CO}_{2}$. Bold indicates significance.

$6 \%$ (comparison of ratios with 1: one-tailed Student test: $T_{168}=1.94$, $P=0.03$, Fig. 5).

If one wasp was drilling and simultaneously engaged in an agonistic interaction with its opponent, drilling had a significant effect on mean $\dot{M}_{\mathrm{CO}_{2}}$ increase (Table 2). We also found a significant effect of interaction type (i.e. kicking, pushing, mounting, chasing, pushing + kicking, pushing + mounting) on mean $\dot{M}_{\mathrm{CO}_{2}}$ increase during the agonistic interaction (Table 2). There was no effect of the duration of the interaction on this increase. Additionally, we found a significant effect of duration and drilling activity when fighting on the increase in maximum instantaneous $\dot{M}_{\mathrm{CO}_{2}}$ during an agonistic interaction (Table 2).

\section{Metabolic costs of drilling}

When drilling and internally probing the host, $\dot{M}_{\mathrm{CO}_{2}}$ of wasps rose significantly (Fig. 2B). The mean drilling ratio $\left(\dot{M}_{\mathrm{CO}_{2}} / \dot{M}_{\mathrm{CO}_{2}, \text { ref }}\right)$ was 1.66 , significantly higher than 1 (one-tailed Student test, $\left.T_{65}=11.245, P<0.001\right)$. Similarly, internal probing also increased the wasp's $\dot{M}_{\mathrm{CO}_{2}}$ (mean ratio=1.40, $T_{56}=8.48, P<0.001$ ). We found an effect of hole feature (i.e. new, reused by the same female, reused from another female) but not of hole position (i.e. egg chorion, seed eye, cotyledon) on mean drilling $\dot{M}_{\mathrm{CO}_{2}}$ (Table 3, Fig. 6A). Post hoc tests using least-squares means revealed that drilling a new hole increased the wasp's metabolic rate more than reusing one $(P=0.04$, Fig. 6A). Other pairwise differences were not significant.

Reusing a hole saved the wasp a significant amount of time (Table 3, Fig. 6C). When drilling a new hole, females needed approximately $8 \mathrm{~min}$ to start probing the host but only $40 \mathrm{~s}$ when reusing one (post hoc tests: $P<0.001$ ). Total energetic costs showed the same pattern as for time costs alone: drilling a new hole was 20 times more energetically costly than reusing one (Table 3 , Figs $6 \mathrm{E}$ and 7). However, we found no effect of hole feature on
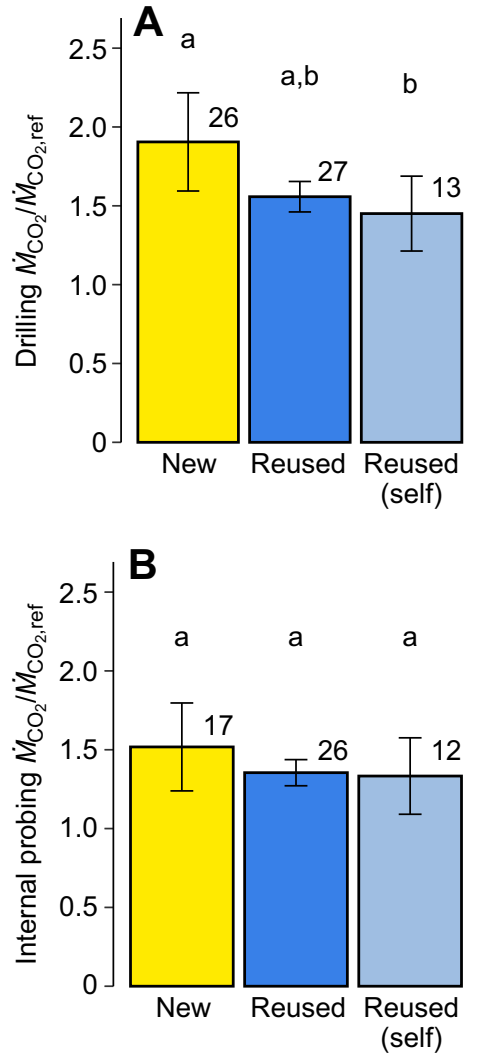
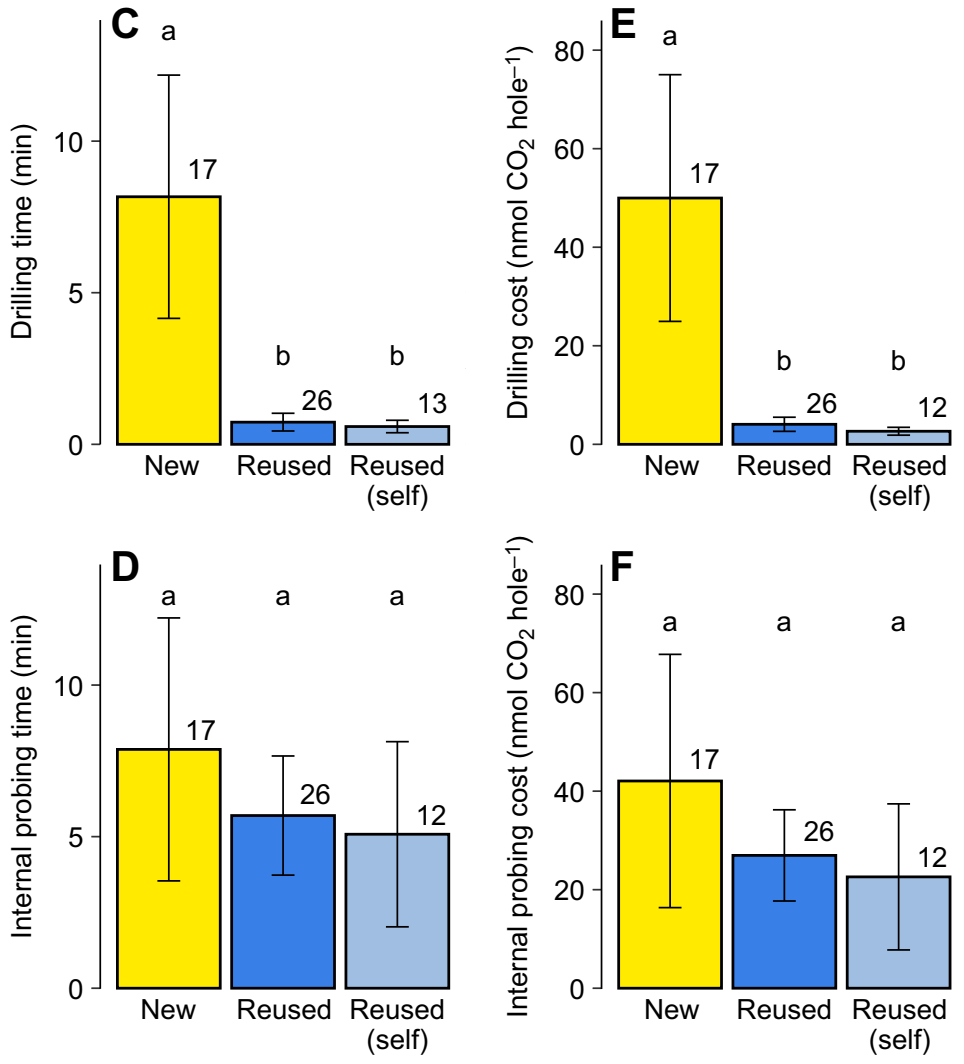

Fig. 6. Metabolic and time costs associated with drilling and internal probing of the host. $(A, B)$ Mean female $\mathrm{CO}_{2}$ production when $(A)$ drilling or (B) internal probing of the host relative to reference $\mathrm{CO}_{2}$ production. $(C, D)$ Mean duration of $(C)$ drilling a complete hole and $(D)$ internal probing of the host through a hole. $(\mathrm{E}, \mathrm{F})$ Mean overall cost of $(\mathrm{E})$ drilling a complete hole (drilling timexmean drilling $\dot{M}_{\mathrm{CO}_{2}}$ ) and $(\mathrm{F})$ internal probing through a hole (probing timexmean probing $\dot{M}_{\mathrm{CO}_{2}}$ ). Bars represent the hole feature, namely whether it is a newly drilled hole, a hole that had previously been drilled by another female (Reused) or a hole that the observed female had drilled earlier in the trial [Reused (self)]. Error bars indicate standard errors. Numbers above bars indicate sample size (number of holes). Data on incomplete holes were only used to compare mean drilling $\dot{M}_{\mathrm{CO}_{2}}$, and were excluded when comparing the time or the overall cost of drilling a hole. Different letters above bars indicate significant differences $(P<0.05)$ using Tukey HSD tests. 
Table 3. Analysis of the effects of hole feature and hole position on drilling $\mathrm{CO}_{2}$ production, drilling time and drilling cost

\begin{tabular}{|c|c|c|c|c|}
\hline Model & Source of variation & d.f. & $F$ & $P$ \\
\hline \multirow[t]{3}{*}{ Drilling $\dot{M}_{\mathrm{CO}_{2}} / \dot{M}_{\mathrm{CO}_{2}, \text { ref }} \sim$ hole feature $\times$ hole position } & Hole feature & 2 & 5.87 & 0.006 \\
\hline & Hole position & 2 & 1.65 & 0.20 \\
\hline & Hole feature: position & 4 & 1.59 & 0.19 \\
\hline & Hole position & 2 & 0.21 & 0.81 \\
\hline & Hole feature: position & 4 & 1.15 & 0.35 \\
\hline log Drilling cost $\sim$ hole featurexhole position & Hole feature & 2 & 73.95 & $<0.001$ \\
\hline
\end{tabular}

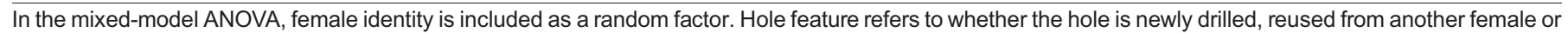
reused by the same female. Hole position refers to the position of the hole on the seed: cotyledon, bruchid egg or seed eye. Bold indicates significance.

$\dot{M}_{\mathrm{CO}_{2}}$ increase, duration or metabolic cost of internal probing (Table S1, Fig. 6B,D,F). Probing the host through the eye of the seed tended to increase $\dot{M}_{\mathrm{CO}_{2}}$ more than probing through a hole drilled through the cotyledon or through the bruchid egg (Table S1, post hoc tests: respectively, $P=0.05$ and $P=0.06$ ). Finally, drilling a new hole was overall three times more expensive than a fight (Fig. 7).

\section{Proportion of the DEE}

Drilling accounted for $15 \%$ of the estimated typical DEE of a wasp. This proportion was calculated based on the hypothesis that the wasp drills new holes to parasitize hosts. Relative to a hypothetical day without drilling, drilling increased DEE by $9 \%$. We estimated that only reusing holes would reduce the wasp's typical DEE by $6 \%$. Finally, one fight (i.e. an entire series of agonistic interactions with a unique opponent) would increase DEE by only $0.001 \%$.

\section{DISCUSSION}

Our results confirmed the hypothesis that the sequence of events leading up to parasitization (fighting with conspecific females, drilling through a cowpea seed) is energetically costly (Fig. 7). However, in the context of the estimated daily energy budget (DEE), the energetic cost of fighting $(0.001 \%$ of DEE) was negligible compared with drilling (15\% of DEE). Contrary to our prediction, fighting resulted in bursts of $\mathrm{CO}_{2}$ production only $6 \%$ higher and mean $\mathrm{CO}_{2}$ production only $23 \%$ higher compared with inactive periods (Fig. 5). These findings shed light on the evolution of superparasitism and fighting behaviors in this system.

\section{Relating energetic costs and fitness costs}

The energetic costs of drilling and fighting will influence the evolution of these behaviors only if they translate into actual fitness costs. According to our estimates, drilling accounts for a large part of the energy budget of a wasp (15\%) and reusing holes may hypothetically save $6 \%$ of the overall DEE of a wasp. Our estimate, however, is limited as we did not directly measure the energy expenditure of our wasps for an entire day. Nevertheless, our estimates are conservative in that actual wasp DEE is probably lower than we assumed. Therefore, reusing holes most likely represents a saving of more than $6 \%$ of the wasp overall DEE compared with drilling new ones every time. Therefore, the energy saved by reusing holes represents a significant fraction of the DEE and probably influences drilling behavior. In contrast, as the energetic costs of contests per se are trivial ( $\sim 0.001 \%$ increase of DEE), they are unlikely to influence fighting behavior.

\section{Why do E. vuilleti females superparasitize?}

Superparasitism appears costly in solitary parasitoids. When laying a supplementary egg on an already infested host, the second female is potentially exposing her offspring to larval competition if the two eggs are likely to hatch within a short period of time. In Pachycrepoideus vindemmiae, the survival probability of the second parasitoid was lower than $50 \%$ and depended on the age of the other larva (Goubault et al., 2003). In E. vuilleti, females facing competition and experiencing low host availability are often observed laying more than one egg per host (Mohamad et al., 2012). Such self-superparasitism may increase the chance that one of the female's offspring will be the one that survives (Van Alphen and Visser, 1990). This competition seems to be reduced by females destroying their opponent's egg (Jaloux, 2004; Leveque et al., 1993). However, females save significant time by reusing an existing hole (Jaloux, 2004). Here, we provide evidence of another benefit of superparasitism in $E$. vuilleti: females can save significant energy by reusing the holes drilled by competitors.

Reusing a hole saves energy and may also facilitate the finding and destruction of a competitor's egg. We are not aware of any formal work on ovicide rate in E. vuilleti in the context of intraspecific competition. However, ovicide rate for eggs of its competitor Dinarmus basalis was on average $18 \%$ and up to $41 \%$ in extreme conditions (van Alebeek and Leveque, 1993). With respect to this benefit, it might be expected that searching for a competitor's egg would lead wasps to probe internally for longer periods of time when reusing holes. However, our data did not bear this out. The benefit of reusing a hole was not counterbalanced by the cost of searching for the opponent's egg to destroy it. By reusing holes, females might also avoid wearing out their ovipositor microstructures, the same way herbivorous insects wear out their mandible when feeding (Bernays, 1991; Raupp, 1985). Finally, it is possible that reducing drilling time limits female exposure to predators. Both ovipositor wear and predator avoidance warrant additional experimental attention.

\section{Why do E. vuilleti females not invest more energy in fights?}

In this study, agonistic interactions carried negligible energetic costs $(0.001 \%$ of DEE). Additionally, the increase of $6 \%$ seen in fighting maximum instantaneous $\dot{M}_{\mathrm{CO}_{2}}$ compared with resting is very small compared with other systems in which the metabolic costs of fighting have been studied: 5 times increase in house crickets (Hack, 1997) and 15 times increase in sierra dome spiders (DeCarvalho et al., 2004). Whether such increases in metabolic rate during fighting in $E$. vuilleti are sufficient to involve anaerobic respiration or result in significant oxidative damage is unknown, though unlikely (Metcalfe and Alonso-alvarez, 2010). Moreover, fights in E. vuilleti are not particularly dangerous and are unlikely to result in injury. Although animal fights can cause injury and even death, most of the time they do not (Green and Patek, 2015; Hardy and Briffa, 2013; Maynard Smith and Price, 1973). Because 


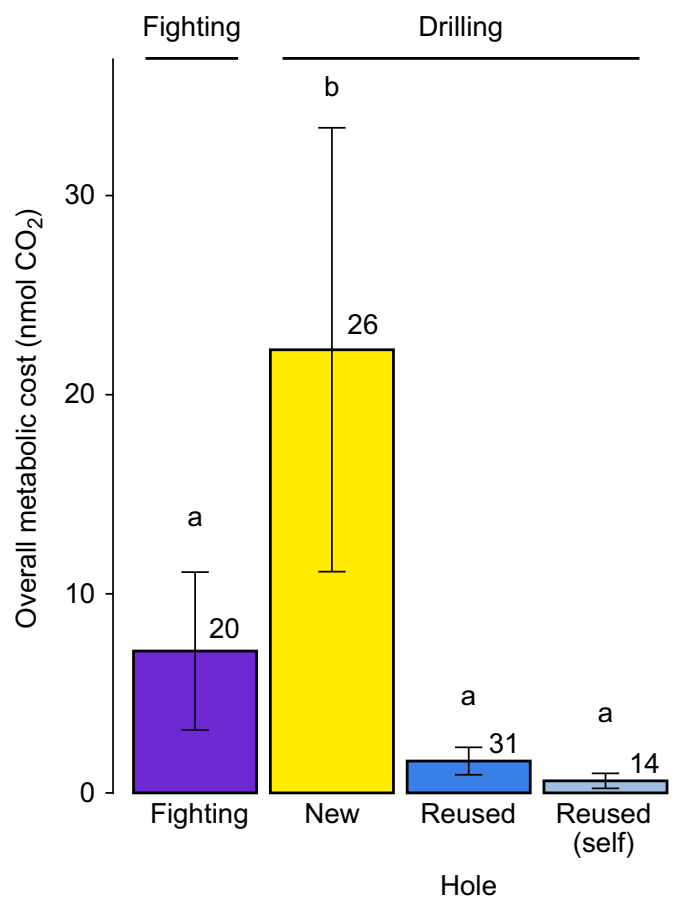

Fig. 7. Comparison of the extra metabolic costs of fighting and drilling activities relative to reference $\mathbf{C O}_{2}$ production. Metabolic costs were calculated as follows: (drilling timexmean drilling $\left.\dot{M}_{\mathrm{CO}_{2}}\right)$-(drilling timex

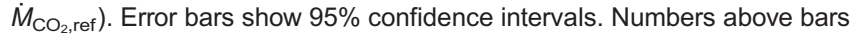
indicate sample size (number of fighting trials or number of holes drilled). Different letters above bars indicate significant differences $(P<0.05)$ using Tukey HSD tests.

our wasps were exposed to a host-poor habitat, we expected that fights would escalate beyond brief kicking and chasing, as resource value should have been high for both contestants. However, in the field, hosts are patchily distributed as bruchid C. maculatus females lay their eggs on mature pods of $V$. unguiculata or directly on the seeds, often stored in traditional granaries (Mohamad, 2012). Field data on the availability of hosts in natural populations of $E$. vuilleti are lacking, but we suspect that finding a host is not difficult. Moreover, E. vuilleti tend to accept already parasitized hosts. Taken together, these facts suggest that the value of a single host is not very high. Contest theory predicts that when the absolute value of accessing a host is small compared with the value of future ones, such as in the case of E. vuilleti (i.e. the female is probably expecting to find another host in the future), then fights are unlikely to escalate (Arnott and Elwood, 2008; Enquist and Leimar, 1990; Hardy and Briffa, 2013). While we did not observe escalation beyond kicks, pushes and chases, even though we provided the females with only one host each day, experience of host availability still affects fighting behavior in E. vuilleti. Females that have experienced a habitat similarly poor in hosts are more aggressive and more likely to win a contest against females that have experienced a host-rich habitat (Mohamad et al., 2010). Moreover, females from a rich habitat that lost a contest avoided fighting in the following one, which was not the case for females from a poor habitat (M. Goubault, M. Exbrayat and R. L. Earley, unpublished). Our data suggest that there may be little benefit to fighting fiercely to access an unparasitized host: winners have to subsequently drill through the seed to lay their eggs on the host, while losers may wait to reuse the drilled holes and save a significant amount of energy.

\section{Is dominance costly in E. vuilleti?}

Asymmetries in pre-contest $\mathrm{CO}_{2}$ production were correlated with contest outcomes in E. vuilleti. This is consistent with previous studies showing that individuals with the highest metabolic rate are the most aggressive and dominant (freshwater prawns: Brown et al., 2003; salmon: Cutts et al., 1999; Metcalfe et al., 1995). For example, in shore crabs, the better competitors had higher concentrations of dopamine, octopamine and serotonin at rest (Sneddon et al., 2000). These neurotransmitters have been associated with increases in heart and ventilation rates, which can be used as proxies for metabolic rate and energy expenditure (Fingerman et al., 1994). Whether such asymmetries in the hormonal status of contestants is also associated with contest outcome in $E$. vuilleti is unknown and will be the subject of future research. Studies showing that dominance status was correlated with a higher metabolic rate referred to such a cost as the 'cost of being dominant' (Bryant and Newton, 1994; Hogstad, 1987; Røskaft et al., 1986). Whether such long-term energetic costs represent a true fitness cost by affecting survival and lifespan, for example, is still unknown.

Many hypotheses may account for the association between metabolic rate and probability of winning. We showed that female wet mass was weakly correlated with metabolic rate. As water content may vary widely between individuals, using dry mass might have helped tighten this relationship. Mass and size are often strongly linked to the resource holding potential of an individual (Hardy and Briffa, 2013). However, mass did not predict contest outcome in our trials or in a previous study (Mohamad et al., 2011), which suggests that another mechanism may be at play. Pre-contest metabolic rate is likely to be a by-product of the physiological capacity of the individual. Observed differences in metabolic rates may directly reflect the differences in fighting ability through differences in metabolic scope (Priede, 1985) or in investment in metabolically costly muscles relative to other tissues (Allen and Levinton, 2007). Individuals with better nutritional status, which are hence in better shape to fight, may have higher metabolic rates, possibly because of food digestion and nutrient absorption (Casas et al., 2015). This hypothesis is rather unlikely in our case as females were reared under the same conditions and should have had similar nutritional status. Another hypothesis is that females with more ready-to-lay eggs should search more actively for hosts and should be more likely to fight for them with other females. A higher egg load will change the subjective value of a single host for a given contestant, thus raising the tolerable cost threshold for that contestant. Indeed, contest outcome in E. vuilleti is strongly driven by asymmetries in egg load: the female with more ready-tolay eggs is more likely to win the contest (Mohamad et al., 2010). Those females may, thus, be more active overall, resulting in a higher observed $\dot{M}_{\mathrm{CO}_{2}}$ (Le Lann et al., 2011). However, we did not find any correlation between egg load and $\dot{M}_{\mathrm{CO}_{2}}$ in our additional subset of females. Future research with larger sample sizes will be needed to investigate whether the association between pre-contest metabolic rate and probability of winning is an epiphenomenon of the correlation between egg load and metabolic rate.

\section{Acknowledgements}

We thank Mylène Exbrayat for help with the experiments; Jerôme Casas and Claudio Lazzari for helpful discussion; Camille Thomas-Bulle, Doug Emlen, Devin O'Brien, Jesse Weber, the Emlen lab and the two anonymous reviewers for considerable feedback on the manuscript; and Thomas Förster (Sable Systems) for providing the R package SableBase.

\section{Competing interests}

The authors declare no competing or financial interests. 


\section{Author contributions}

Conceptualization: R.P.B., H.A.W., M.G.; Methodology: R.P.B., H.A.W., M.G.; Software: H.A.W.; Validation: R.P.B., H.A.W., M.G.; Formal analysis: R.P.B., H.A.W., M.G.; Investigation: R.P.B.; Resources: H.A.W., M.G.; Data curation: R.P.B.; Writing - original draft: R.P.B.; Writing - review \& editing: R.P.B., H.A.W., M.G.; Visualization: R.P.B.; Supervision: H.A.W., M.G.; Project administration: H.A.W., M.G.; Funding acquisition: R.P.B., H.A.W., M.G.

\section{Funding}

This project was supported in part by the University of Montana (Missoula, MT, USA) and the Institut de Recherche sur la Biologie de l'Insecte (IRBI, Université François Rabelais, Tours, France). R.P.B. was funded by the Ecole Normale Supérieure (Paris, France)

\section{Supplementary information}

Supplementary information available online at

http://jeb.biologists.org/lookup/doi/10.1242/jeb.160887.supplemental

\section{References}

Adamo, S. A. and Parsons, N. M. (2006). The emergency life-history stage and immunity in the cricket, Gryllus texensis. Anim. Behav. 72, 235-244.

Allen, B. J. and Levinton, J. S. (2007). Costs of bearing a sexually selected ornamental weapon in a fiddler crab. Funct. Ecol. 21, 154-161.

Arnott, G. and Elwood, R. W. (2008). Information gathering and decision making about resource value in animal contests. Anim. Behav. 76, 529-542.

Austad, S. N. (1983). A game theoretical interpretation of male combat in the bow and doily spider (Frontinella pyramitela). Exp. Gerontol. 31, 59-73.

Bartholomew, B. Y. G. A., Vleck, D. and Vleck, C. M. (1981). Instantaneous measurements of oxygen consumption during pre-flight warm-up and post-flight cooling in sphingid and saturniid moths. J. Exp. Biol. 90, 17-32.

Bernays, E. A. (1991). Evolution of insect morphology in relation to plants. Philos. Trans. R. Soc. Lond. B. Biol. Sci. 333, 287-264.

Briffa, M. and Sneddon, L. U. (2007). Physiological constraints on contest behaviour. Funct. Ecol. 21, 627-637.

Brown, J. H., Ross, B., McCauley, S., Dance, S., Taylor, A. C. and Huntingford, F. A. (2003). Resting metabolic rate and social status in juvenile giant freshwater prawns, Macrobrachium rosenbergii. Mar. Freshw. Behav. Physiol. 36, 31-40.

Bryant, D. M. and Newton, A. V. (1994). Metabolic costs of dominance in dippers, Cinclus cinclus. Anim. Behav. 48, 447-455.

Casas, J., Body, M., Gutzwiller, F., Giron, D., Lazzari, C. R., Pincebourde, S., Richard, R. and Llandres, A. L. (2015). Increasing metabolic rate despite declining body weight in an adult parasitoid wasp. J. Insect Physiol. 79, 27-35.

Chelazzi, G., Focardi, S., Deneubourg, J. L. and Innocenti, R. (1983) Competition for the home and aggressive behaviour in the chiton Acanthopleura gemmata (Blainville) (Mollusca: Polyplacophora). Behav. Ecol. Sociobiol. 14, 15-20.

Clarke, A. and Fraser, K. P. P. (2004). Why does metabolism scale with temperature? Funct. Ecol. 18, 243-251.

Clutton-Brock, A. T. H. and Albon, S. D. (1979). The roaring of red deer and the evolution of honest advertisement. Behaviour 69, 145-170.

Copeland, D. L., Levay, B., Sivaraman, B., Beebe-Fugloni, C. and Earley, R. L. (2011). Metabolic costs of fighting are driven by contest performance in male convict cichlid fish. Anim. Behav. 82, 271-280.

Cortesero, A. M. (1994). La recherche de l'hôte chez Eupelmus vuilleti (CRW): analyse des relations tritrophiques entre la plante (Vigna unguiculata walp), l'hôte (Bruchidius atrolineatus pic) et le parasitoïde. PhD thesis, University François Rabelais, Tours, France.

Cutts, C. J., Metcalfe, N. B. Taylor, A. C. (1999). Competitive asymmetries in territorial juvenile Atlantic salmon, Salmo salar. Oikos 86, 479-486.

Danchin, É., Giraldeau, L.-A. and Cézilly, F. (2005). Écologie comportementale. In Écologie Comportementale: Cours et Questions de Reflexion, pp. 664. Paris Dunod.

DeCarvalho, T. N., Watson, P. J. and Field, S. A. (2004). Costs increase as ritualized fighting progresses within and between phases in the sierra dome spider, Neriene litigiosa. Anim. Behav. 68, 473-482.

Dunn, M., Copelston, M. and Workman, L. (2004). Trade-offs and seasonal variation in territorial defence and predator evasion in the European Robin Erithacus rubecula. Ibis (Lond. 1859) 146, 77-84.

Enquist, M. and Leimar, O. (1990). The evolution of fatal fighting. Anim. Behav. $39,1-9$.

Fingerman, M., Nagabhushanam, R., Sarojini, R. and Reddy, P. S. (1994) Biogenic amines in crustaceans: identification, localization, and roles. J. Crustac. Biol. 14, 413-437.

Godfray, H. C. J. (1994). Parasitoids: Behavioral and Evolutionary Ecology Princeton. Princeton University Press.

Goubault, M., Plantegenest, M., Poinsot, D. and Cortesero, A. M. (2003). Effect of expected offspring survival probability on host selection in a solitary parasitoid. Entomol. Exp. Appl. 109, 123-131.
Green, P. A. and Patek, S. N. (2015). Contests with deadly weapons: telson sparring in mantis shrimp (Stomatopoda). Biol. Lett. 11, 20150558.

Hack, M. A. (1997). The energetic costs of fighting in the house cricket, Acheta domesticus L. Behav. Ecol. 8, 28-36.

Hardy, I. C. W. and Briffa, M. (2013). Animal Contests. Cambridge: Cambridge University press.

Hildner, K. K. and Soule, M. E. (2004). Relationship between the energetic cost of burrowing and genetic variability among populations of the pocket gopher, $T$ bottae: does physiological fitness correlate with genetic variability? J. Exp. Biol. 207, 2221-2227.

Hogstad, O. (1987). It is expensive to be dominant. Auk 104, 333-336.

Jakobsson, S., Brick, O. and Kullberg, C. (1995). Escalated fighting behaviour incurs increased predation risk. Anim. Behav. 49, 235-239.

Jaloux, B. (2004). La discrimination interspécifique par Eupelmus vuillet (Hymenoptera: Eupelmidae) des hôtes parasités par Dinarmus basalis (Hymenoptera: Pteromalidae). PhD thesis, University François Rabelais, Tours, France.

Jaloux, B., Sanon, A., Huignard, J. and Monge, J. P. (2004). Interspecific relationships between the solitary ectoparasitoid, Eupelmus vuilleti (Crw.) (Eupelmidae), and its sympatric species, Dinarmus basalis (Rond.) (Pteromalidae), in the presence of their host. Callosobruchus maculatus pic (Coleoptera Bruchidae). J. Insect Behav. 17, 793-808.

Koteja, P. (1987). On the relation between basal and maximum metabolic rate in mammals. Comp. Biochem. Physiol. A Physiol. 87A, 205-208.

Krebs, C. J. (2008). The Ecological World View. Oakland, CA: University of California Press.

Kundanati, L. and Gundiah, N. (2014). Biomechanics of substrate boring by fig wasps. J. Exp. Biol. 217, 1946-1954.

Leimar, O. and Enquist, M. (1984). Effects of asymmetries in owner-intruder conflicts. J. Theor. Biol. 111, 475-491.

Le Lann, C., Wardziak, T., van Baaren, J. and van Alphen, J. J. M. (2011) Thermal plasticity of metabolic rates linked to life-history traits and foraging behaviour in a parasitic wasp. Funct. Ecol. 25, 641-651.

Leveque, L., Monge, J.-P., Rojasrousse, D., Vanalebeek, F. and Huignard, J. (1993). Analysis of multiparasitism by eupelmus-vuilleti (Craw) (Eupelmidae) and dinarmus-basalis (Rond) (Pteromalidae) in the presence of one of their common hosts, bruchidius-Atrolineatus (Pic) (Coleoptera Bruchidae). Oecologia 94 $272-277$

Lighton, J. R. B. (2008). Measuring Metabolic Rates: A Manual for Scientists. Oxford: Oxford University Press.

Luna, F. and Antinuchi, C. D. (2006). Cost of foraging in the subterranean roden Ctenomys talarum: effect of soil hardness. Can. J. Zool. Can. Zool. 84, 661-667. Maynard Smith, J. (1974). The theory of games and the evolution of animal conflicts. J. Theor. Biol. 47, 209-221.

Maynard Smith, J. and Price, G. R. (1973). Logic of animal conflict. Nature 246, 15-18.

Maynard Smith, J. and Parker, G. A. (1976). The logic of asymmetric contests Anim. Behav. 24, 159-175.

Metcalfe, N., Taylor, A. and Thorpe, J. (1995). Metabolic rate, social status and lifehistory strategies in Atlantic salmon. Anim. Behav. 49, 431-436.

Metcalfe, N. B. and Alonso-alvarez, C. (2010). Oxidative stress as a life-history constraint : the role of reactive oxygen species in shaping phenotypes from conception to death. Funct. Ecol. 24, 984-996.

Mohamad, R. (2012). Compétition intra- et interspécifique chez deux parasitoïdes sympatriques: résolution des conflits et conséquences sur les stratégies d'exploitation des hôtes. PhD thesis, University François Rabelais, Tours, France.

Mohamad, R., Monge, J.-P. and Goubault, M. (2010). Can subjective resource value affect aggressiveness and contest outcome in parasitoid wasps? Anim. Behav. 80, 629-636.

Mohamad, R., Monge, J.-P. and Goubault, M. (2011). Agonistic interactions and their implications for parasitoid species coexistence. Behav. Ecol. 22, 1114-1122.

Mohamad, R., Monge, J.-P. and Goubault, M. (2012). Wait or fight? Ownership asymmetry affects contest behaviors in a parasitoid wasp. Behav. Ecol. 23 , 1330-1337.

Mowles, S. L., Cotton, P. A. and Briffa, M. (2009). Aerobic capacity influences giving-up decisions in fighting hermit crabs: does stamina constrain contests? Anim. Behav. 78, 735-740

Murray, M. G. and Gerrard, R. (1985). Putting the challenge into resource exploitation: a model of contest competition. J. Theor. Biol. 115, 367-389.

Neat, F. C., Taylor, A. C. and Huntingford, F. A. (1998). Proximate costs of fighting in male cichlid fish: the role of injuries and energy metabolism. Anim. Behav. $\mathbf{5 5}$, 875-882

Parker, G. A. (1974). Assessment strategy and the evolution of fighting behaviour. J. Theor. Biol. 47, 223-243.

Priede, I. G. (1985). Metabolic scope in fishes. In Fish Energetics (ed. P. Tyrtler and P. Calow), pp. 33-64. Berlin: Springer.

Quicke, D. L. J., Leralec, A. and Vilhelmsen, L. (1999). Ovipositor structure and function in the parasitic hymenoptera with an exploration of new hypotheses. Atti dell' Accademia Nazionale Italiana di Entomologia, 197-239. 
Raupp, M. J. (1985). Effects of leaf toughness on mandibular wear of the leaf beetle, Plagiodera versicolora. Ecol. Entomol. 10, 73-79.

Riechert, S. E. (1988). The energetic costs of fighting. Am. Zool. 28, 877-884.

Røskaft, E., Järvi, T., Bakken, M., Bech, C. and Reinertsen, R. E. (1986). The relationship between social status and resting metabolic rate in great tits (Parus major) and Pied Flycatchers (Ficedula hypoleuca). Anim. Behav. 34, 838-842.

Rovero, F., Hughes, R. N., Whiteley, N. M. and Chelazzi, G. (2000). Estimating the energetic cost of fighting in shore crabs by noninvasive monitoring of heartbeat rate. Anim. Behav. 59, 705-713.

Singer, F. and Riechert, S. E. (1995). Mating system and mating success of the desert spider Agelenopsis aperta. Behav. Ecol. Sociobiol. 36, 313-322.

Smith, I. P. and Taylor, A. C. (1993). The energetic cost of agonistic behaviour in the velvet swimming crab, Necora (=Liocarcinus) puber (L.). Anim. Behav. 45, 375.

Sneddon, L. U., Taylor, A. C. and Huntingford, F. A. (1999). Metabolic consequences of agonistic behaviour: crab fights in declining oxygen tensions. Anim. Behav. 57, 353-363.
Sneddon, L. U., Taylor, A. C., Huntingford, F. A. and Watson, D. G. (2000). Agonistic behaviour and biogenic amines in shore crabs Carcinus maenas. J. Exp. Biol. 203, 537-545.

Stockermans, B. C. and Hardy, I. C. W. (2013). Subjective and objective components of resource value additively increase aggression in parasitoid contests. Biol. Lett. 9, 20130391.

Terrasse, P. C. and Rojas-Rousse, D. (1986). Distribution de la ponte et évitement du superparasitisme chez l'hyménoptère solitaire Bruchocida vuilleti Cwf. (Hym., Eupelmidae), parasite des stades larvaires de son hôte, Callosobruchus maculatus F. (Col., Bruchidae). J. Appl. Entomol. 101, 243-256.

van Alebeek, F. A. N. and Leveque, L. (1993). Interspecific competition between Eupelmus vuilleti and Dinarmus basalis, two solitary ectoparasitoids of Bruchidae larvae and pupae. Entomol. Exp. Appl. 69, 21-31.

Van Alphen, J. J. M. and Visser, M. E. (1990). Superparasitism as an adaptive strategy for insect parasitoids. Annu. Rev. Entomol. 35, 59-79. 